\title{
Performance testing of a downdraft biomass gasifier stove for cooking applications
}

\author{
Woranuch Jangsawang ${ }^{1, *}$ \\ ${ }^{1}$ Sustainable Energy Research Center, Department of Energy Engineering, Faculty of Industrial \\ Technology, Phranakhon Rajabhat University, 10220 Bangkok, Thailand.
}

\begin{abstract}
A down draft biomass gasifier stove with four steps of cleaning gas system was developed to produce the producer gas for replacing LPG for cooking applications in lunch project for the student in rural school area. This project has been implemented at Bangrakam primary school that located at Pitsanuloke Province, Thailand. The biomass fuels used are Mimosa wood twigs. The gasifier stove was developed based on down draft fixed bed gasifier with the maximum fuel capacity of fourteen kilograms. The performance testing of the biomass gasifier stove showed that the heating value of the producer gas is $4.12 \mathrm{MJ} / \mathrm{Nm}^{3}$ with the thermal efficiency in the percentage of 85.49. The results from this study imply that it has high potential to replace LPG with producer gas.
\end{abstract}

\section{Introduction}

Energy is one of the important fundamental factors for human being in this era. The human being need to use energy in variety forms for daily life activities in which including with direct energy and indirect energy usage. From the problem of energy crisis that be facing in every country around the world and also in Thailand according to the conventional energy from fossil fuels in the form of oil, natural gas and etc. that be mostly used and they are going less. Thailand has limited of fossil fuel resources however the primary energy consumption mostly still based on fossil fuels thus all major commercial energies have to be imported. The impact of energy import on the economy is significant. The total cost of energy import has been rising, from the data in the report of energy statistics of Thailand 2015 showed that the average value of energy imported from the year of 2010 to 2014 was at 1,290,332.95 million Thai baht [1]. Thus the energy production from renewable energy resources to substitute the energy consumption from conventional energy is urgent need of the country [2]. Thailand is an agricultural rich country. There are variety kind of biomass that can be used as energy fuels such as wood, short rotation plant, agricultural residual and etc. [3]. Biomass conversion is the process to change biomass fuel to useful energy by extraction of the organic compounds in biomass. There are two main processes to convert biomass to useful energy such as thermochemical and biochemical conversion process. Biomass that has high moisture content mostly uses biochemical conversion process but for biomass that has low moisture content mostly use thermochemical conversion process [4]. In the present time, cooking food in household and cooking applications in small and medium enterprises mostly use liquefied petroleum gas as fuel. The favour of using

\footnotetext{
*Corresponding author: woranuch@pnru.ac.th
} 
liquefied petroleum gas according to its convenience and easy for operation but the price of LPG has been rising. This will affect directly on the expenditure of the people. However in rural area the people still use wood and charcoal as fuel for cooking. Thus a down draft biomass gasifier stove with four steps of cleaning gas system was developed to produce the producer gas for replacing of LPG for cooking applications in lunch project for the student in rural school. This project is the pilot project to promote using of biomass that available in the community for producing of the producer gas for cooking applications in primary school in Thailand. This project has been implemented at Bangrakam Primary School located at Bangrakhram District,Pitsanuloke Province, Thailand. Mimosa is a kind of weed in which it can grow and reproduction very fast. It is unwanted flora and available in the school and community around the school. Thus the main biomass fuel used for this project is Mimosa wood twig. This will save the energy budget for cooking and decreasing the environmental impacts from using fossil fuel. Thus the objective of this study is to examine the thermal performance of biomass gasifier stove. The results provided from this study are aimed to increased use of biomass in gasifier with the producer gas replacing LPG for small and medium enterprises.

\section{Research Objectives}

\subsection{Materials}

\subsubsection{Gasifier system}

A down draft biomass gasifier stove with the consumption rate of 14 kilograms per hour has been designed and fabricated to use in this project. The down draft biomass gasifier stove comprises of four steps of cleaning gas system was used in this study The cleaning gas system comprises of cyclone, wet scrubber, coarse bag filter and fine bag filter.The pictorial of a downdraft biomass gasifier stove with four steps of cleaning gas system showed in Figure 1.

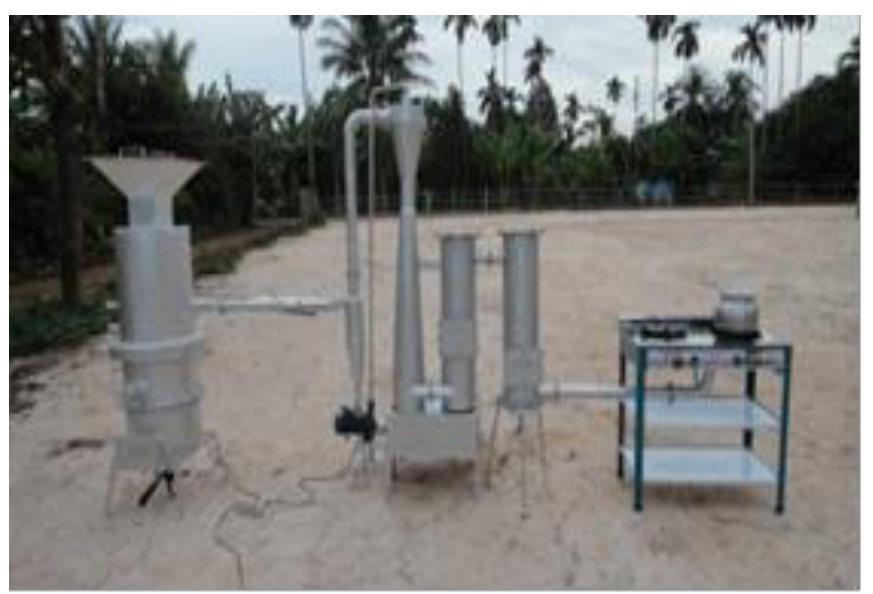

Fig 1. A downdraft biomass gasifier stove with four steps of cleaning gas system

\subsubsection{System}

Mimosa wood twig was used as biomass fuel in this study. The Mimosa wood twigs were prepared by cutting in to small pieces. The length of each piece is around 30 millimetres. 
The pictorial of mimosa wood twigs that be used as biomass fuel in this study was shown in Figure 2.

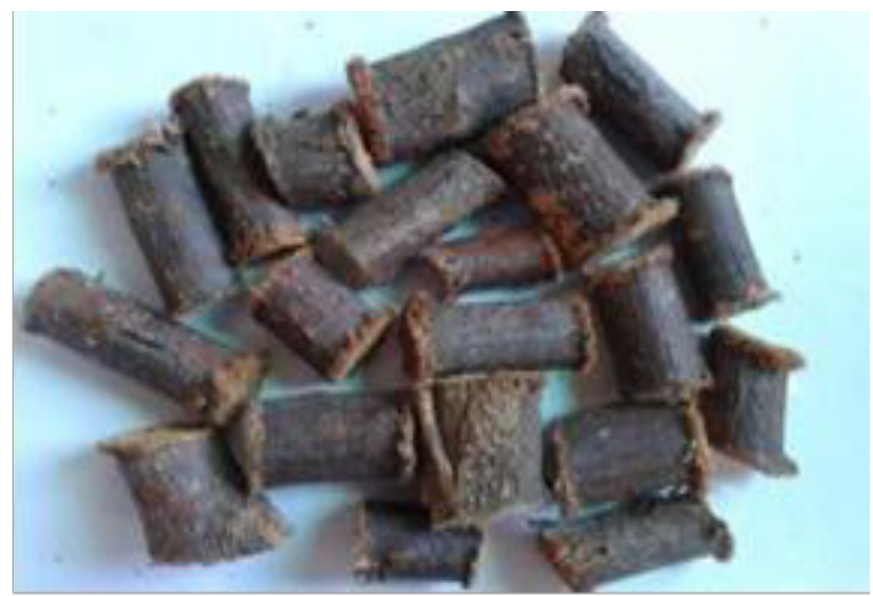

Fig 2. Mimosa wood twigs that be used as biomass fuel.

\subsection{Method}

To investigate the thermal performance of a downdraft biomass gasifier stove when using mimosa wood twig as biomass fuel, the series of experiments were conducted as follows:

\subsubsection{Examine the temperature within the gasifier at 4 different points to study the} temperature distribution at different zone within downdraft biomass gasifier stove.

The temperature within gasifier was measured with thermocouples at 4 different zones as $T_{1}, T_{2}, T_{3}$ and $T_{4}$ respectively. $T_{1}$ was installed at the position of twenty centimetres below the air supply point to measure the temperature of producer gas at outlet. $\mathrm{T}_{2}$ was installed to measure the temperature distribution at reduction zone. $\mathrm{T}_{3}$ was installed at air supply point to measure the temperature distribution at combustion zone. $\mathrm{T}_{4}$ was installed above air supply point to measure the temperature distribution at pyrolysis zone. The pictorial of installed thermocouples to measure the temperature distribution within gasifier was shown in Figure 3. 


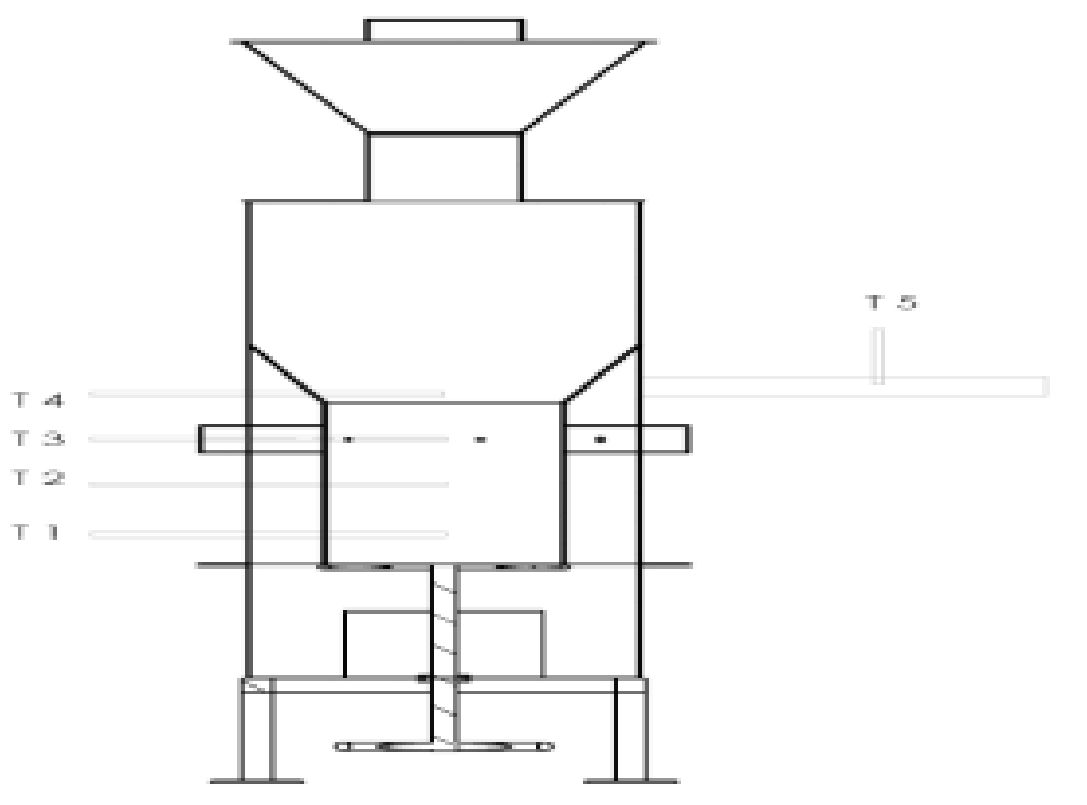

Fig 3.The pictorial of installed thermocouples to measure the temperature distribution within gasifier.

\subsubsection{Examine the amount and composition of producer gas produced from gasifier when using mimosa wood twigs as biomass fuel.}

To investigate the performance of biomass gasifier stove, the amount of producer gas produced from the gasification process was measured by follow the European tar measurement standard [5]. The producer gas will be collected by taking gas sampling and analysed by using gas chromatography. The sample gas will be pumped through into the series of four impinger bottles and then pass through the gas filter before pumped into the gas sampling bag. The impinger bottles will fill with the isopropanol solution to dissolve tars that accumulate in the producer gas.

\subsubsection{Calculate the heating value of the producer gas.}

The composition of producer gas will be analysed by using gas chromatography. Then the heating value of the combustible gas compose in the producer gas in unit of $\mathrm{MJ} / \mathrm{Nm}^{3}$ was calculated by using equation 1 [6].

$$
\mathrm{G}_{\mathrm{LHV}}=\left((\mathrm{CO} \% \times 12.63)+\left(\mathrm{CH}_{4} \% \times 35.88\right)+\left(\mathrm{H}_{2} \% \times 10.78\right)\right) / 100
$$

\subsubsection{Calculate the performance of biomass gasifier stove.}

The thermal efficiency of the gasification system was investigated by comparing between the energy content of the biomass used and the energy content of the producer gas produced. The thermal efficiency of the gasification system was calculated by using equation 2.

$$
\eta \text { th }=\left(Q_{G} \times L H V_{G}\right) \times 100 /\left(m_{f} \times L H V_{f}\right)
$$




\section{Result and Discussion}

\subsection{The temperature distribution within gasifier when using mimosa wood twig as biomass fuel.}

The temperature distribution within gasifier when using mimosa wood twig as biomass fuel showed in Figure 4. The results showed that the thermocouple of $\mathrm{T}_{3}$ that be installed at about the air supply point showed the highest temperature. The temperatures are in the range of 772-1044 degree Celsius. The average temperature at this zone is about 783 degree Celsius. These results imply that this zone is the combustion zone of downdraft gasifier stove. For the thermocouple $T_{4}$ that be installed above of $T_{3}$, the results showed that the temperatures are in the range of 125- 492 degree Celsius. The average temperature at this zone is 174 degree Celsius. These results imply that this zone is pyrolysis zone. For the thermocouple $T_{2}$ that be installed below the position of $T_{3}$, the average temperature at this zone is 501 degree Celsius. These results imply that this zone is reduction zone. At the thermocouple of $\mathrm{T}_{1}$ showed that the temperature distribution at this zone is almost steady. The average temperature is 120 degree Celsius. These results imply that this area is the position of gas outlet.

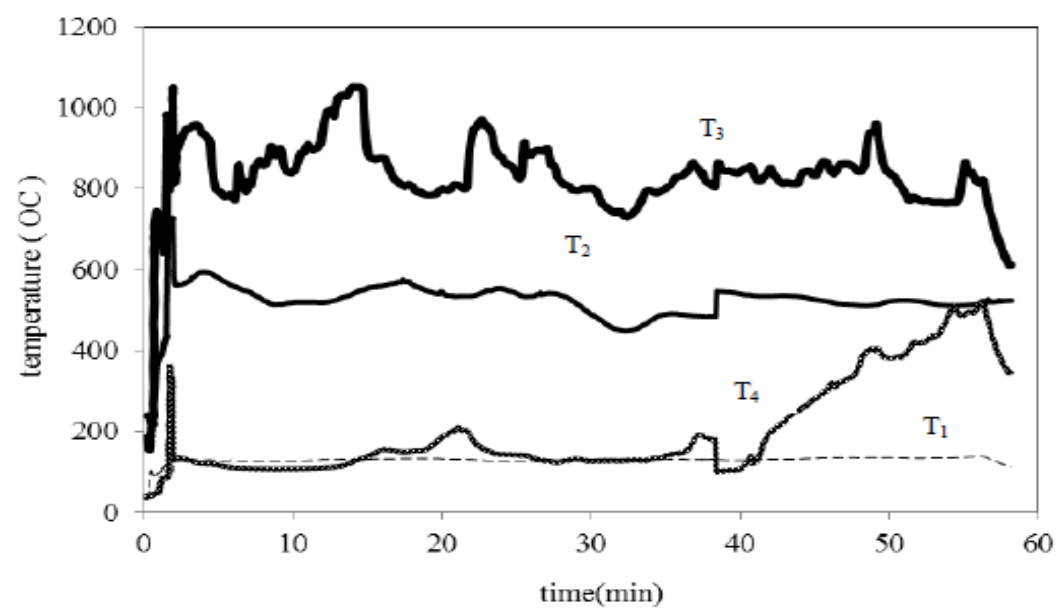

Fig 4. The temperature distributions within gasifier when using mimosa wood twig as biomass fuel.

\subsection{The amount and heating value of producer gas produced from the gasifier stove.}

The heating value of producer gas calculates from three main of combustible gas such as $\mathrm{CO}, \mathrm{CH}_{4}$ and $\mathrm{H}_{2}$. The amount of producer gas produced from gasifier by using Mimosa wood twig as biomass fuel was shown in Table 1.

Table 1. The amount and heating value of producer gas produced.

\begin{tabular}{|c|c|}
\hline producer gas & amount (\%by volume) \\
\hline $\mathrm{CO}$ & 18.99 \\
\hline $\mathrm{CH}_{4}$ & 0.75 \\
\hline $\mathrm{H}_{2}$ & 13.44 \\
\hline
\end{tabular}


From the results of the amount of the three main compositions in the producer gas, the heating value of producer gas was calculated by using equation 1 . The result showed that heating value of the producer gas produced from Mimosa wood twig is $4.12 \mathrm{MJ} / \mathrm{Nm}^{3}$. This result implies that the heating value of producer gas is in the range of producer gas produced with air as gasifying agent [7].The efficiency of downdraft biomass gasifier system was calculated by comparing between input energy and output energy. The input energy is the energy comes from the heating value of Mimosa wood twig. From the heating value of Mimosa wood twig is $16.19 \mathrm{MJ} / \mathrm{kg}$ and rate of fuel consumption is $4 \mathrm{~kg} / \mathrm{hr}$. The output energy is the energy comes from the heating value of three main components of producer gas. From the result of heating value of the producer gas produced from Mimosa wood twig is $4.12 \mathrm{MJ} / \mathrm{Nm}^{3}$ with the flow rate of producer gas is $14.11 \mathrm{~m}^{3} / \mathrm{hr}$. Then the efficiency of the biomass gasifier system was calculated by using equation 2 . The result showed that the thermal efficiency of downdraft biomass gasifier system is in the percentage of 85.49 .

\section{Conclusion}

The results of using Mimosa wood twig as biomass fuel for producing the producer gas in a downdraft biomass gasifier stove to replace of using LPG has advantage in variety aspects are as follow :

- Down draft biomass gasifier with four steps of cleaning gas system is suitable for using in institutional or small and medium enterprise. That is because the gasifier system is easy for operation and produces the clean gas with blue flame.

- Mimosa wood twig has high potential to use as biomass fuel. That is because it is weed that available in community and can supply with cheap or no cost. And the heating value is high when comparing with other biomass.

- The thermal efficiency of gasifier system is in the percentage of 85.49.

- The heating value of producer gas is $4.12 \mathrm{MJ} / \mathrm{Nm}^{3}$.

The results provided from this study will help to promote using of biomass gasifier for small and medium enterprises. This will save the energy budget for cooking and decreasing the environmental impacts from using fossil fuel. The results from this study imply that it has high potential to replace LPG with producer gas.

\section{References}

1. Energy policy and planning office (EPPO), The energy statistics of Thailand 2015 (Energy policy and planning office, Bangkok, 2015)

2. Ministry of Energy, Alternative Energy Development Plan:AEDP 2015 (Ministry of Energy, Bangkok, 2015)

3. P. Suwanakuta and P. Suwanakuta. Proceeding of the $2^{\text {nd }}$ joint international conference on sustainable energy and environment (SEE 2006) (2006)

4. Bhattacharya S.C. Augustus Leon M and Aung Mit Khaing. paper presented in international seminar on appropriate for fuel production from biomass Yogyakarta Indonesia (2003)

5. J.P.A Neeft Senternovem, CEN BT/TF 143 organic contaminants (tar) in biomass producer gas Netherland (Netherland, 2005)

6. Basu P, Biomass Gasification and Pyrolysis :Practical Design and Theory (Elsevier, USA, 2010)

7. Mckendry P Energy Production from Biomass (part 3):Gasification Techniques Bioresources Technology (2002) 